\title{
Self-reported motivation for choosing nursing studies: a self-determination theory perspective
}

\author{
Linda Messineo ${ }^{*+}$ (D), Mario Allegra ${ }^{\dagger}$ and Luciano Seta ${ }^{\dagger}$
}

\begin{abstract}
Background: The nursing shortage is of worldwide concern, with nursing student retention acknowledged as a priority. As a fundamental step towards exploring factors that can guide the implementation of strategic approaches to retain undergraduate nursing students and prevent their attrition, the aim of this study is to examine the motivation for choosing nursing studies of first-year nursing students within the theoretical framework of self-determination theory.

Methods: We conducted a study at the Medical School of the University of Palermo. A total of 133 first-year nursing students completed a two-part questionnaire: a measure of socio-demographic aspects and an open question about their motivation for choosing nursing studies. Students' responses were analysed using thematic analysis.

Dimensional analysis was performed in order to verify an organization along one dimension, in agreement with the differentiation of the autonomous and controlled types of motivation of self-determination theory. A person-centred approach was utilised to define motivational profiles able to characterize clusters of students according to both quality and quantity of motivation.

Results: A set of 18 categories was developed. The factor analysis has shown that nursing students' motivations can be organized along one dimension, in alignment with the differentiation of the autonomous and controlled forms of motivation of self-determination theory. Through adoption of a person-centred approach, four motivational profiles were identified: a) students with good quality motivation profile (high autonomous and low controlled); b) students with poor quality motivation profile (low autonomous and high controlled); c) students with low quantity motivation profile (low autonomous and low controlled); d) students with low quantity and poor quality motivation profile (i.e. prevalence of controlled motivation).

Conclusions: Importance of this research includes the possibility to interpret nursing students' reasons within the theoretical framework of self-determination theory, a well-grounded model able to offer useful information to academic nursing schools, in order to promote effective strategies to foster and support student motivation.

Keywords: Autonomous motivation, Choosing nursing, Content analysis, Controlled motivation, Nursing students, Self-determination theory
\end{abstract}

\section{Background}

Nursing is a profession of vital importance. Nurses play a significant role in the promotion of health, prevention of disease and care of the sick. The shortage of nurses in health systems is of worldwide concern $[1,2]$ and also poses a number of challenges to the educational system.

*Correspondence: linda.messineo@itd.cnr.it

${ }^{\dagger}$ Linda Messineo, Mario Allegra, and Luciano Seta contributed equally to this work.

Istituto per le Tecnologie Didattiche, Consiglio Nazionale delle Ricerche, via Ugo La Malfa 153, 90146 Palermo, Italy

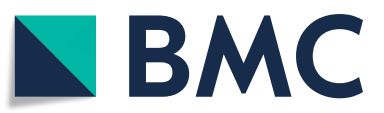

(c) The Author(s). 2019 Open Access This article is distributed under the terms of the Creative Commons Attribution 4.0 International License (http://creativecommons.org/licenses/by/4.0/), which permits unrestricted use, distribution, and reproduction in any medium, provided you give appropriate credit to the original author(s) and the source, provide a link to the Creative Commons license, and indicate if changes were made. The Creative Commons Public Domain Dedication waiver (http://creativecommons.org/publicdomain/zero/1.0/) applies to the data made available in this article, unless otherwise stated.
The nursing student attrition rate is one of the factors that negatively affects the satisfaction of health professional workforce demand. Planning approaches to promote the retention of undergraduate nursing students, especially during the first year, is a strategy to face the challenges of the shortfall of qualified nurses. The efficacy of these strategies requires better comprehension of the factors associated with nursing student attrition through fostering and supporting specific affective factors positively related to retention, and reducing modifiable factors 
positively related to attrition. Different levels and types of reasons and factors contributing to nursing students' attrition have been identified [3-8]. Personal reasons for leaving, institutional, political, societal and occupational factors are reported [9]. Researchers have also examined how both students' personal characteristics, such as study motivation, and environmental aspects influence their retention [4, 10-12]. Motivation is a construct that may influence student retention, academic achievement and persistence behaviours [11].

In the present study, the focus is on undergraduate student motivation in choosing nursing studies and the nursing profession. Comprehending the career motives for this choice is important in order to design specific strategies to promote undergraduate nursing student retention [13-15].

Motivation is a complex construct with multiple components. It is the result of a set of processes of activation and orientation of behaviour and action, aimed at the realization of a specific purpose. In the multifaceted process of choosing an academic degree course and a career, different sources, goals and reasons which drive intentional actions are present as co-occurring factors $[14,16]$. Student reasons for choosing a nursing university course and nursing as a career have been explored in several research studies. These studies have shown that this choice is a result of a combination of different motivations. The most frequent reasons found in the literature are the wish to help other people, the desire to engage in activities and to perform a job which is socially beneficial, career opportunities and job security, the positive image of the specific role of nurses, the influence of family members or friends [17-23]. Personal experiences, such as hospitalization, illness of a family member, are identified as additional motivations for the choice [18-20]. In all research, help for others and altruism are the motivational factors for the career choice most frequently reported by students.

These motivations, due to their frequent occurrence, are often generic and their use can make it difficult to clearly understand the actual motivational process behind the student's declaration. So, a similar term may refer to an internal process (such as a personal interest or internal pressure), or an external one (parental influence, peer pressure, situational factors, etc.). Any strategy that want to increase nursing students' retention and set up efficient learning approaches, has to be based on a deeper understanding of their motivations. The use of structured questionnaires can help to avoid some inconsistencies. These tools are not very simple to implement, and the interpretation of the results requires a deep knowledge of the theory supporting their creation. Generally, the constructs are rigorously defined and the questions are strictly focused to measure only these factors. On the other hand, the use of open questions simplifies the gathering of selfreported motivations, and allows students to describe their beliefs and emotions about their choice of the degree course. However, it transfers to the researcher the demanding task of interpreting the students' answers, and does not allow them to extend the results beyond the specific study.

This study illustrates how the theoretical framework of self-determination theory (SDT) [24, 25] can be used as a common framework for interpreting the self-reported reasons for choosing nursing studies, collected responding to an open question. This result will allow educationalists to construct shared strategies, once they have obtained a clear 'motivational landscape' characterizing the students of a particular degree course.

SDT is a theory of human motivation that hypothesizes that people pursue goal content through different regulatory processes. It identify three different categories of motivation that extend along a continuum of increasing self-determination: amotivation, controlled motivation and autonomous motivation [24]. Along this dimension, it is possible to distinguish specific types of regulatory styles, that vary in their degree of relative autonomy: from external to intrinsic regulation.

The self-determination continuum, showing the motivational, self-regulatory, and perceived locus of causality bases of behaviours that vary in the degree to which they are self-determined, is illustrated in Fig. 1.

Amotivation is the state of lacking an intention to act $[24,25]$. Amotivated individuals are neither intrinsically motivated nor extrinsically motivated [26].

Extrinsic motivation can vary greatly in the degree to which it is autonomous and it refers to pursuing a goal for reasons that are external to the activity itself. Considering the amount of relative autonomy, four types of regulation are recognized, namely external regulation, introjected regulation, identified regulation and integrated regulation [24, 25]. The continuum of motivation varies in term of the extent to which the objective of a behaviour has been internalized. Externally regulated motivation is the classic case of extrinsic motivation. It is low in self-determination, and the origin of individual' behaviours is a particular external contingency, such as the achievement of an external reward that is considered to be positive, or the avoidance of a consequence perceived as negative. The control of goaldirected activity is entirely external. Introjected regulation refers to people that pursue goal directed behaviours for specific contingencies and consequences administered by individuals to themselves. Introjected regulation has been in part internalized, but it is a relatively instable form of regulation [24, 26]. External regulation and introjected regulation can be classified as controlled motivation. 


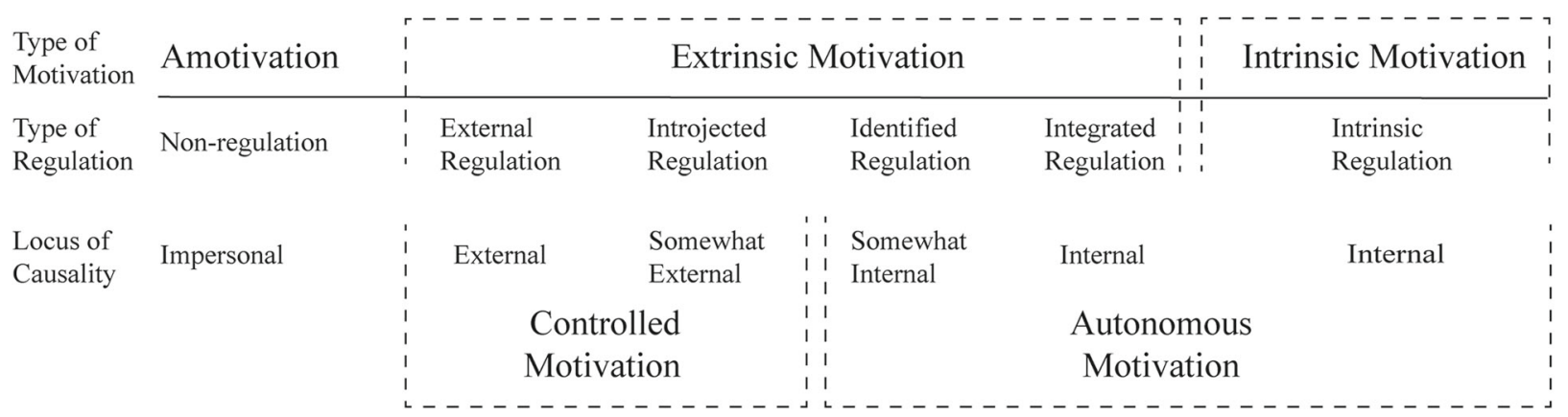

Fig. 1 The self-determination continuum, showing the motivational, self-regulatory, and perceived locus of causality bases of behaviours that vary in the degree to which they are self-determined (adapted from Deci \& Ryan, 2000)

Identified regulation is a more autonomous form of extrinsic motivation. Identification is a process through which people comprehend the value of an activity, and regulation is more internalized. The control is internal and the activity is sustained by self-regulation, and the objective has a value for the person.

Integrated regulation is the most autonomous form of extrinsic motivation. Integration is the process through which people perform an activity, integrating the identification with some aspect of the self. The control and the regulation are internal. Individuals feel competent when they perform an activity, and consider the activity as meaningful. An integrated regulation motivational state shares more characteristics with intrinsic motivation. Nevertheless, the activity is carried out to obtain a goal or outcomes that are different from the activity itself.

Finally, intrinsic motivation is a prototype of selfdetermined choice and activity. When intrinsically motivated, individual pursue a goal because of the inherent feeling of pleasure, enjoyment and satisfaction in the activity. The purpose corresponds with the activity itself. SDT suggests that people are intrinsically motivated to do something when they have the opportunity to autonomously choose meaningful activities that support their self-expression and that allow them to use their competence.

Identified and integrated regulation can be classified as well-internalized motivations; well-internalized and intrinsic motivations are the two subcomponents of autonomous motivation.

Many research studies have investigated the relationship between motivation and learning. Student motivation influences learning, study behaviour and achievement, and it is related to academic success [27]. Research shows that autonomous motivation profiles are associated to more successful learning outcomes and success, over time, than controlled motivation [28, 29].
Moreover, autonomous motivation is associated to the use of deep cognitive strategy and reflection in learning [30, 31]. Intrinsically motivated students persist much more in an academic task [31, 32]. Students with an autonomous profile, referred to high levels of autonomous motivation and low levels of controlled motivation, perform optimal learning patterns [33], and they are more persistent in an academic program than students with other motivational profiles [34]. Besides, intrinsic motivation may prevent academic disengagement [29].

Consequently, to understand the quality of personal motivation, in terms of controlled vs. autonomous, is a preliminary objective for any interventions aimed at reducing attrition and improving academic success.

The aim of the present study was to identify, using a qualitative research approach, representative categories able to summarise the content of first-year students' selfreported motivations for choosing nursing studies. The categories were analysed within the theoretical framework of the self-determination theory, in order to verify their organization along a continuum scale, ranging from controlled to autonomous motivation.

Although previous qualitative studies that investigate self-reported motivation for choosing nursing studies are different, they have not usually examined students' motivational statements from an SDT perspective. In a research study the statements on motivations of applicants for medical studies were analysed within an SDT framework [35]. This study shows that reasons of applicants mainly concerned autonomous motivations.

\section{Methods}

\section{Methodological orientation and theory}

In this study, a methodology is proposed to overcome some of the biases typical of self-report data. The qualitative analysis of the nursing students' answers was integrated with multi-dimensional scal- 
ing techniques aimed at interpreting the results of the qualitative analysis in the theory-grounded framework of SDT.

The student nurses' answers have been elaborated using qualitative and quantitative methods. The qualitative analysis was aimed at interpreting an abundant variety of personal information about career and study choices, instead of using defined tests in career choices, in which students have to select from limited answer options. The outcome of this analysis was a group of categories summarizing the main identified reasons.

The quantitative analysis used the SDT framework to organize the categories along the dimension controlled/autonomous. This allowed a comparison between the results of this study and other studies that used scales to measure student nurse motivation, giving external confirmation of the validity of the proposed interpretation.

\section{Participants and procedure}

The study was conducted at the School of Medicine of the University of Palermo. According to the local ethical policy, no prior formal authorization approval by the Ethics Committee was necessary. We communicated the qualitative study design to the Institutional board of the Undergraduate Nursing Course guaranteeing that ethical standards would be met and we received approval.

Data collection was carried out on entry to the nursing degree course, at the beginning of the first month of the first semester. All undergraduate students $\left(N_{t o t}=140\right)$ enrolled in the first year of the nursing degree were invited to participate in the study. One researcher (LM), a general psychology teacher in the nursing degree course, invited students attending her lectures to participate in the study.

After a general psychology teaching session, LM communicated the following information: (a) the aim of the research was illustrated; (b) participation was voluntary, and students could decide to interrupt their participation at any moment; (c) the students were reassured about the confidentiality of the data collected, which was only managed by researchers; (d) each name was replaced with a unique code number.

During the same session, LM presented the procedure for taking part in the study. Data was collected by filling in an on-line questionnaire by means of a web-platform structured for the purposes of the present research. Data was retrieved only after obtaining voluntary informed consent, in the presence of LM. The duration of the entire session was about 30 minutes.

\section{Measures}

The questionnaire consisted in a two-part form: a) demographic survey aimed at gathering some demographic data about the students; b) motivation for choosing nursing studies.
Demographic survey. The demographic questions were concerned with basic demographic information such as age and sex. Students were also asked if they had previously attended other university courses and if so, specify the name of the degree course.

Motivation for choosing nursing studies. An open question was asked to gather information about student motivation regarding their decision to enrol on the university nursing course. Students had to answer the question: "Describe your reasons for choosing the nursing degree course".

\section{Data analyses and results}

The number of first-year nursing students who participated in the study and answered all questions was $N=133$. Seven students chose to not participate in the research. Participants included a total of 84 females (63\%) and 49 males (37\%), aged from 18 to $41\left(M_{\text {age }}=21.7\right.$ years, $S D=4.31$ ). Demographic data of student participants, regarding gender and age distribution, are reported in Table 1.

Thirty-six percent of the students had previously attended other university courses. Previous university student enrolments mainly consisted of attending healthcare sector courses, like pharmacy and psychiatric rehabilitation techniques $(9 \%)$ or health-related sectors such as biology, biotechnology and motor science university courses (10\%). Seven percent of the students had previously enrolled in humanistic disciplines, such as psychology and philosophy. The others students (10\%) attended courses in scientific subjects, such as engineering, economics and information technology.

Table 1 Demographic characteristics of nursing students

\begin{tabular}{llll}
\hline Characteristics & $\mathrm{n}$ & $\%$ & Age: Mean (SD) \\
\hline Gender & 49 & 37 & $22.22(4.72)$ \\
Males & 84 & 63 & $21.32(4.04)$ \\
Females & 133 & 100 & $21.70(4.31)$ \\
Total & & & \\
Age groups & 50 & 38 & $18.80(0.40)$ \\
$18-19$ & 43 & 32 & $20.26(0.44)$ \\
$20-21$ & 40 & 30 & $26.73(4.85)$ \\
$22-41$ & & & \\
Previous university experience & & & \\
Healthcare sector courses & 26 & 19 & $22.50(4.62)$ \\
or health-related sectors & 9 & 7 & $27.11(6.01)$ \\
Humanistic disciplines & 13 & 10 & $23.77(5.15)$ \\
Scientific subjects & 74 & 56 & $20.35(2.96)$ \\
No previous university experience & 11 & 8 & $20.18(2.36)$ \\
Non-responses & & &
\end{tabular}




\section{Thematic analysis}

The students' answers to the open question were analysed using qualitative methods [36]. Two independent evaluators (the first and third authors of this study) scrutinised and coded the content of the open questions. LM is a psychologist and researcher, an expert in cognitive and clinical psychology, conducting research on education and motivation, and is familiar with the literature on SDT. LS is a PhD researcher, an expert in applied mathematics, data analysis and modelling, and is familiar with the literature on cognitive sciences. The process of category selection followed four phases. In the first phase, after an in depth reading of students' responses, the two evaluators independently carried out an analytic segmentation of the contents, with the aim of identify distinct nuclei of meaning. To describe the content, they suggested some categories. In this phase, each evaluator added a brief explanation to the category and some phrases extracted from the students' answers, to highlight the meaning of the category. In the second phase, the two evaluators compared their categories in order to select a common bundle. During the phase three, the evaluators read all the answers again independently, selecting one or more among the categories previously defined for each subject. On average three categories were selected for each subject $(M=2.82, S D=1.17)$. Finally, the two evaluators met to compare their selection. The few discrepancies revealed were resolved through discussion. An initial set of 18 categories was developed. Tables 2 and 3 summarise the results of thematic analysis with a description of the inferred categories.

As described in Table 3, the most frequent reasons expressed by students are the desire to help others (HEL), often associated with the desire to being useful (USE) and have contact with other people in a healthcare setting (HUM). These students often consider their choice like a mission (MIS) or a vocation (VOC). The second most frequent motivation is regarding job opportunities (JOB). This type of motivation, probably connected to the current socio-economic situation, reveals the increasing demand for a nursing job, in the face of an increasing demand for healthcare services. The attraction of the image of the nursing role (ROL) is often associated with rewarding aspect of the profession (GRA and SMI). Students described their personal interest in the topics (TOP). Personal experience (EXP) such as job experience (e.g. volunteering), or hospitalization, having a relative with an illness, etc., are described by students. Some students referred that their skills, abilities or personal characteristics they think to possess are essential for the nursing profession (MIR). Role model influence was another typology of driving motivation: family tradition (FAM) and recommendations of family members and friends (REC) were described. It is also important to highlight that the choice of a nursing degree course isn't always the first option ( $\mathrm{SCH}$ ), for example, some students weren't able to pass admission tests in other preferred degree courses.

When one compares the frequencies of the different categories with respect to gender and age, some differences are apparent (see Table 3). In females' replies are recurrent the categories that refer to the feeling of usefulness (USE, HEL, VOC, HUM, MIS), rewarded with a smile (SMI, GRA), or to the pursuit of specific career goals, such as specialisation in midwifery (TAR). In males' answers the prevailing motivations are more oriented to the search for social security, status (JOB), or knowledge-wish fulfilment (CUR). Taking age into consideration, the younger students appear more oriented toward categories related to personal fulfilment, such as seeking human contact (HUM) and an engagement in activities with applicative implications (PRA). The older students seem to give more weight to motivations attributable to the search for social status and security, such as looking for new job opportunities (JOB), or following friends/parents' recommendations (REC).

\section{Dimensional analysis}

Although the results of the qualitative analysis are in good agreement with the research literature about the choice of the nursing degree course, without a theoretical framework, these agreement could sound purely anecdotal. A first look at the whole corpus of answers suggests good homogeneity in the motivations expressed by the students, after considering individual linguistic and communicative differences. According to the SDT approach [24], a latent dimension seems to emerge from their answers, along which the subjects can be distributed along a continuum ranging from controlled to autonomous motivation. To confirm this hypothesis, the first step was to verify the possibility of organizing the obtained categories, described in Table 2, along one latent dimension, corresponding to controlled/autonomous in the SDT approach. The factor analysis (FA) is the dimension reduction method elective in these cases. For this dichotomous data, literature suggests to work with a tetrachoric correlation matrix [37]. The construction of this matrix starts from the matrix $\mathrm{G}$ of the co-occurrences of the $m$ observed categories, $C_{i}$, with $i=1, \ldots, m$. The element $G_{i j}$ of the matrix $\mathrm{G}$ (see lower triangle in Table 4) represents the number of subjects in which the categories $C_{i}$ and $C_{j}$ are both present. The tetrachoric correlation was applied using these values (see upper triangle in Table 4).

The sample size $(N=133)$ and the number of the selected categories $(m=18)$ limit the validity of the FA. Some authors have suggested a sample size of at least 200 subjects and ratios of sample size to categories between 5 to 20 [38-41]. Further studies have highlighted that these 
Table 2 Inductively inferred categories

\begin{tabular}{lll}
\hline Category & Code & Brief description \\
\hline Be useful & USE & The desire to feel useful \\
Curiosity & CUR & The desire of knowledge \\
Family tradition & FAM & $\begin{array}{l}\text { Family tradition: one or more components } \\
\text { of the family is a healthcare professional, a } \\
\text { nurse, a doctor, etc. }\end{array}$ \\
Gratification & & $\begin{array}{l}\text { To consider nursing profession a rewarding } \\
\text { profession. }\end{array}$
\end{tabular}

Characteristic phrase (code number)

"The wish to be useful to others." (264)

"I like to be useful and to help people." (70)

"The desire to be helpful to others." (106)

"I chose this degree course because I have always been fascinated by the world of health care." (36)

"I chose a degree course that would guarantee me a more immediate professional future ... in addition to this motivation, another factor comes into play, even more important, namely the desire for knowledge." (105)

"I chose the nursing degree course for various reasons. First of all, because I have relatives in the medical field who have passed on the desire to help suffering people." (157)

"I have relatives that are nurses and doctors; they introduced me to this world." (149)

"I grew up in an environment full of doctors." (286)

"... my motives are also family based, in fact my father is a nurse and I would be happy to follow in his footsteps." (110)

"I consider nursing a rewarding field, in fact a series of actions to improve the patient's condition of health are carried out! I consider nursing a rewarding profession!" (9)

"I think I would feel gratified at the end of the day knowing that I helped." (122)

"It (this work) is something that gratifies me, that makes me feel good, that satisfies me." (202)

"I think that helping people who are ill and who are in difficulty is one of the most satisfying things that gratifies them." (18)

Helping others HEL The desire to help others.

"I think that helping sick people is absolutely one of the most rewarding things, which gratifies you." (18)

"I want to take care of others." (168)

"The idea of being able to help people really appeals to me." (266)

Human contact HUM Seeking human contact.

"I really love being in close contact with people." (188)

"l like to have personal contact with people." (182)

"l love to interact with people." (258)

Mission

MIS To consider nursing profession as a mission

Personal experience EXP Personal experience, such as job experience (e.g. volunteering), hospitalization, a relative with an illness, etc.

Personality

Skills, abilities or personal characteristics that students think they possess.

Practical

PRA Oriented to manual and practical applications
"Ensuring that people who suffer are able to find not only a good nurse, but also an angel of consolation. We have to get to know them and to serve them with love." (131)

"Helping people suffering is a mission to be pursued." (36)

"I've always wanted to make a contribution to society, helping others because a nurse's job is really a mission." (150)

"The motivation that has driven me to this decision was the death of my grandparents (death due to illness), and the death of a special good friend, who died long ago, at a much too early age." (36)

"I had a painful personal experience, therefore I realized that my pathway was to help people." (64)

"The choice was reinforced also by many personal 'negative' experiences in hospitals during the last few years of my life." (44)

"This desire began after an event that occurred in my family." (43)

"In addition to the skill acquired by study and practice, it need a strong sense of humanity, with patience, kindness and firmness. I think I have these personal characteristics." (65)

"I am a person who can listen and help ...I think anyone who wants to undertake this type of profession should have this kind of personality." (35) "Helping others has always been in my nature." (187)

"Helping those in need ...not from behind a desk, but doing something concretely, with a hands-on approach." (191)

"I like the curriculum which includes not only theoretical topics but also practical aspects." (184) 
Table 2 Inductively inferred categories (Continued)

\begin{tabular}{|c|c|c|c|}
\hline Category & Code & Brief description & Characteristic phrase (code number) \\
\hline & & & $\begin{array}{l}\text { "In this degree course, we will be immediately brought into contact with the } \\
\text { concrete work, we will put into practice what we study." (221) }\end{array}$ \\
\hline & & & "It allows me to do something concrete to help others." (251) \\
\hline \multirow[t]{3}{*}{ Recommendation } & REC & $\begin{array}{l}\text { Recommendations of family members and } \\
\text { friends. }\end{array}$ & $\begin{array}{l}\text { "...thanks to different orientation services of the university and also after } \\
\text { talking with friends, I realized that my future would be right in this course of } \\
\text { study." (158) }\end{array}$ \\
\hline & & & $\begin{array}{l}\text { "My girlfriend is in the third year (of nursing degree course) and she } \\
\text { inspired me a lot." (182) }\end{array}$ \\
\hline & & & "Friends also influenced me to make this choice." (230) \\
\hline \multirow[t]{2}{*}{ Role of the nurse } & $\mathrm{ROL}$ & Attraction of the image of the nursing role. & $\begin{array}{l}\text { "I have always been attracted by the figure of the nurse as a person that } \\
\text { is in direct contact with people and therefore has a very crucial role of } \\
\text { responsibility." (1) }\end{array}$ \\
\hline & & & $\begin{array}{l}\text { "I have chosen a nursing degree course because I think the nurse is one of the } \\
\text { most noble and important jobs in the world of work." (94) }\end{array}$ \\
\hline \multirow[t]{5}{*}{ Second choice } & $\mathrm{SCH}$ & $\begin{array}{l}\text { The choice of a nursing degree course } \\
\text { isn't the first option (for example, students } \\
\text { weren't able to pass admission tests in other } \\
\text { preferred degree courses). }\end{array}$ & $\begin{array}{l}\text { "I am a first year student at this university course, after l obtained a university } \\
\text { degree in philosophy. Clearly, this is not a choice motivated by passion, } \\
\text { because philosophy was my first choice, but motivated by the desire to find } \\
\text { a future career." (230) }\end{array}$ \\
\hline & & & $\begin{array}{l}\text { "... because last year, I wasn't admitted to a physiotherapy degree course." } \\
\text { (163) }\end{array}$ \\
\hline & & & $\begin{array}{l}\text { "I wasn't admitted to a medical degree course, then I choose this degree } \\
\text { program." (222) }\end{array}$ \\
\hline & & & $\begin{array}{l}\text { "Nursing is my second choice. In fact, I will would like to attend the course of } \\
\text { medicine." (258) }\end{array}$ \\
\hline & & & "Nursing was my eighth choice." (75) \\
\hline \multirow[t]{4}{*}{ Secure Job } & $J O B$ & Job opportunities. & $\begin{array}{l}\text { "I made the decision to choose a course of study that would guarantee me a } \\
\text { job opportunity." (105) }\end{array}$ \\
\hline & & & "I was driven by the possibilities of employment at European level." (182) \\
\hline & & & "This degree course offers many opportunities of employment." (198) \\
\hline & & & $\begin{array}{l}\text { "The first (motivation) concerns job opportunities, in fact, the percentage of } \\
\text { graduates who find a job after the first year is very high." (188) }\end{array}$ \\
\hline \multirow[t]{4}{*}{ Smile } & SMI & People's smiles are rewarding. & $\begin{array}{l}\text { "Helping others and seeing them happy would be gratifying for me, because } \\
\text { I would have contributed to their lives." (44) }\end{array}$ \\
\hline & & & "... give a smile to people who need it." (198) \\
\hline & & & "I love the smiles of people." (288) \\
\hline & & & $\begin{array}{l}\text { "Being useful to others, to give them a smile to relieve their suffering,..., is } \\
\text { something that would make me completely satisfied." (161) }\end{array}$ \\
\hline \multirow[t]{3}{*}{ Topics } & TOP & Interest in science subjects. & $\begin{array}{l}\text { "The main reason why I enrolled in this degree course is because I have a } \\
\text { preference for scientific topics, such as biology and chemistry." (109) }\end{array}$ \\
\hline & & & $\begin{array}{l}\text { "I have a great passion for healthcare and science subjects such as biology, } \\
\text { anatomy, etc." (49) }\end{array}$ \\
\hline & & & "Interest in topics concerning the health sector." (87) \\
\hline \multirow[t]{2}{*}{ Vocation } & VOC & $\begin{array}{l}\text { The intention or desire to be a nurse is } \\
\text { present from many years. }\end{array}$ & $\begin{array}{l}\text { "From my early childhood, I felt that the role of this profession was right for } \\
\text { me." (139) }\end{array}$ \\
\hline & & & "I always wanted to be a nurse." (152) \\
\hline \multirow[t]{3}{*}{ Well targeted } & TAR & $\begin{array}{l}\text { The choice is motivated by a specific career } \\
\text { goal. }\end{array}$ & $\begin{array}{l}\text { "When I think about my future, I see myself in the operating room assisting a } \\
\text { surgeon." (165) }\end{array}$ \\
\hline & & & "After I graduate, I will be able to specialize in obstetrics."(126) \\
\hline & & & $\begin{array}{l}\text { "I enrolled in this course because my ambition is to become a scrub nurse in } \\
\text { the operating room." (2) }\end{array}$ \\
\hline
\end{tabular}

requirements are dependent on specific characteristics of the data, such as the magnitude of the communalities, magnitudes of the loadings, the number of factors, and the number of variable for factors [42]. The data obtained in this study are near the lower limit, established by the standards, to obtain a significant estimation for the parameters of the factorial model. To better understand the validity of the FA results, the Kaiser-Meyer-Olkin Measure of Sampling Adequacy (KMO MSA) was calculated, a wellknown indicator of the common variance within a data set $[43,44]$. Nine categories were above the threshold of 0.5 $\left(M S A_{i}>.5\right)$ (in bold in Table 5). 
Table 3 Summary of students' responses using categories described in Table 2

\begin{tabular}{lllll}
\hline Code & $n_{i}$ & $n_{i} / N$ & Age $_{i}$ & $F_{i} / n_{i}$ \\
\hline HEL & 78 & .59 & 20.7 & .64 \\
JOB & 44 & .33 & 22.9 & .48 \\
ROL & 31 & .23 & 21.6 & .68 \\
SCH & 27 & .20 & 23.0 & .59 \\
TOP & 27 & .20 & 21.1 & .78 \\
VOC & 25 & .19 & 22.4 & .72 \\
EXP & 23 & .17 & 21.2 & .70 \\
MIR & 21 & .16 & 21.3 & .71 \\
HUM & 19 & .14 & 19.7 & .68 \\
USE & 18 & .14 & 20.4 & .78 \\
FAM & 11 & .08 & 21.7 & .55 \\
PRA & 10 & .08 & 19.7 & .70 \\
REC & 9 & .07 & 23.1 & .56 \\
TAR & 9 & .07 & 20.6 & .78 \\
GRA & 9 & .07 & 20.6 & .67 \\
SMI & 7 & .05 & 19.3 & 1.0 \\
CUR & 4 & .03 & 24.5 & .25 \\
MIS & 3 & .02 & 20.7 & .67 \\
\hline
\end{tabular}

In columns: $n_{i}$, absolute frequency of each category; $n_{i} / N(N=133$ sample size), relative frequency of each category; $A g e_{j}$, mean age for each category, 21.7 (SD $=4.3$ ) mean (SD) age of sample; $F_{i} / n_{i}$, females for category (females in the sample $63 \%)$.
In Table 6 the results of the FA are summarised. This result was obtained by means of a factor analysis, with one latent variable, and an oblique factor with a minimizing criterion.

Ordering the categories according to the increasing values of the factor loadings, it is possible to interpret the result as a distribution of the categories along the latent dimension. Table 7 shows the results of this ordering. Considering the meaning of the categories summarised in Table 2, this pattern is in agreement with an interpretation of the latent dimension evidenced by the SDT approach. The distribution of the categories seems to reproduce a classification in which on the left-hand side there are categories related to a controlled motivation, while moving to the right there are more autonomous categories. In fact, the controlled motivations are externally regulated, that is typical of subjects with an external perceived locus of causality. In the types of controlled motivation, the search for a job (JOB), family and social recommendation (FAM and REC) are included. It is also possible to include motivations that are more internal, but not sufficiently internalized, because they are not related to the specific activities that the students will go on to do (PRA and TOP). Categories strictly linked to primary needs, such as relatedness (HEL and HUM), competence (EXP), and autonomy (SMI and MIR) belong to the type of autonomous motivations. It is also interesting to note

Table 4 Co-occurences and tetrachoric correlation matrices

\begin{tabular}{lllllllllllllllllll}
\hline & HEL & JOB & ROL & SCH & TOP & VOC & EXP & MIR & HUM & USE & FAM & PRA & REC & TAR & GRA & SMI & CUR & MIS \\
\hline HEL & 78 & -.198 & -.168 & -.124 & -.368 & .031 & .364 & .067 & .337 & .053 & -.045 & -.373 & -.162 & .119 & -.015 & .511 & -.353 & 0.53 \\
JOB & 22 & 44 & -.196 & .100 & -.132 & -.090 & -.388 & .001 & -.209 & .195 & .041 & -.035 & .520 & -.150 & -.146 & -.420 & -.100 & -.248 \\
ROL & 15 & 7 & 31 & -.101 & .001 & .123 & -.190 & -.073 & -.284 & -.097 & .083 & .253 & .000 & -.345 & -.166 & -.154 & .053 & .361 \\
SCH & 14 & 10 & 5 & 27 & -.038 & -.005 & -.066 & -.149 & .130 & -.387 & .114 & -.211 & .567 & .206 & -.180 & -.275 & .066 & -.094 \\
TOP & 10 & 7 & 6 & 5 & 27 & -.213 & -.451 & -.022 & .128 & .057 & -.036 & -.002 & .037 & -.173 & .056 & -.110 & .080 & -.124 \\
VOC & 15 & 7 & 7 & 5 & 3 & 25 & .086 & .120 & -.069 & -.180 & .302 & .342 & -.155 & -.321 & -.311 & -.086 & -.135 & -.101 \\
EXP & 18 & 3 & 3 & 4 & 1 & 5 & 23 & .168 & .300 & -.132 & -.344 & -.334 & -.287 & .119 & -.089 & .362 & .141 & .151 \\
MIR & 13 & 7 & 4 & 3 & 4 & 5 & 5 & 21 & .340 & -.306 & -.160 & .086 & -.091 & .134 & -.263 & .206 & -.084 & -.057 \\
HUM & 15 & 4 & 2 & 5 & 5 & 3 & 6 & 6 & 19 & -.089 & -.140 & -.289 & -.082 & -.257 & .157 & .009 & -.073 & -.005 \\
USE & 11 & 8 & 3 & 1 & 4 & 2 & 2 & 1 & 2 & 18 & .116 & .144 & -.049 & -.036 & -.022 & -.187 & -.038 & .229 \\
FAM & 6 & 4 & 3 & 3 & 2 & 4 & 0 & 1 & 1 & 2 & 11 & .303 & -.101 & -.110 & -.101 & -.076 & .077 & .096 \\
PRA & 3 & 3 & 4 & 1 & 2 & 4 & 0 & 2 & 0 & 2 & 2 & 10 & .104 & -.098 & -.094 & -.034 & .088 & .142 \\
REC & 4 & 7 & 2 & 6 & 2 & 1 & 0 & 1 & 1 & 1 & 0 & 1 & 9 & -.056 & -.047 & -.044 & .129 & .126 \\
TAR & 6 & 2 & 0 & 3 & 1 & 0 & 2 & 2 & 0 & 1 & 0 & 0 & 0 & 9 & -.037 & .210 & .129 & .119 \\
GRA & 5 & 2 & 1 & 1 & 2 & 0 & 1 & 0 & 2 & 1 & 0 & 0 & 0 & 0 & 9 & .201 & .139 & .362 \\
SMI & 7 & 0 & 1 & 0 & 1 & 1 & 3 & 2 & 1 & 0 & 0 & 0 & 0 & 1 & 1 & 7 & .156 & .235 \\
CUR & 1 & 1 & 1 & 1 & 1 & 0 & 1 & 0 & 0 & 0 & 0 & 0 & 0 & 0 & 0 & 0 & 4 & .574 \\
MIS & 2 & 0 & 2 & 0 & 0 & 0 & 1 & 0 & 0 & 1 & 0 & 0 & 0 & 0 & 1 & 0 & 1 & 3 \\
\hline
\end{tabular}

Lower diagonal: the co-occurrences $G_{i j}$ of categories in students' answers, the terms on diagonal correspond to $n_{i}$. Upper diagonal: tetrachoric correlation between two categories. 
Table 5 Results of the test of Kaiser-Meyer-Olkin $\mathrm{MSA}_{i}$ (in bold the categories over the threshold 0.5)

\begin{tabular}{llllllllllllllllll}
\hline HEL & JOB & $R O L$ & $S C H$ & TOP & VOC & EXP & MIR & HUM & USE & FAM & PRA & REC & TAR & GRA & SMI & CUR & MIS \\
$\mathbf{. 5 7}$ & $\mathbf{. 5 1}$ & .45 & .46 & .43 & $\mathbf{. 5 5}$ & $\mathbf{. 6 1}$ & .49 & $\mathbf{. 5 0}$ & 0.45 & $\mathbf{. 5 3}$ & $\mathbf{. 6 0}$ & $\mathbf{. 5 0}$ & .41 & .38 & $\mathbf{. 6 1}$ & .42 & .47 \\
\hline
\end{tabular}

that the more extreme categories, in bold in Table 7 , are also the categories with values above the threshold of 0.5 in the KMO MSA test (see Table 5), with the exception of the category VOC.

This led us to perform a confirmatory factor analysis (CFA) using only 8 categories, the categories best able to identify the quality of the motivation. From the types of controlled motivation, we used the categories JOB, REC, PRA, and FAM. We used the categories EXP, HUM, HEL, and SMI for the types of autonomous motivation.

For this analysis, a logistic model with 2 parameters was applied. This model is particularly appropriate for analysing binary data [45]. According to the unidimensional Item Response Theory (IRT), using a similar model with two parameters permits to obtain two different estimations for each category: the simplicity of the selection (intercept) and the ability of each category to discriminate the motivational profile of the students (slope). The results of the model are summarised in Table 8 . The value of the intercept is correlated with the frequency of each category in the students' answers. The slope is more interesting. The sign of the slope divides the category into two types of motivations, the categories with negative slopes corresponding to the controlled motivation (JOB, FAM, PRA and REC); the categories with positive values of the slope correspond to the autonomous motivation (HEL, EXP, HUM and SMI).

The dependent variable of the logistic model measures the level of internalization of student motivation, in relation to the decision to attend the specific degree course. For each student, the detection of a category with negative slope moves her/him toward a poorer motivational profile, and the detection of a category with a positive slope moves her/him toward a richer profile. Using the estimations of the model, a person-centred analysis can be carried out. This analysis allows for the assignment of a motivational score to each student, according to the pattern of categories extracted from her/his answer.

The distribution of these scores has a mean about zero $(M=0.015, S D=.756)$. The test of Shapiro-Wilk makes it possible to reject the hypothesis of normality ( $W=$ $.972, p<.01)$. The estimated value of the skewness, $g_{1}=.201$ ( $s e=.212$ ), highlights the fact that the mass of the distribution is concentrated on the left, i.e. on the controlled types of motivation (see Fig. 2).

Analysing the differences in the scores distribution for gender and age groups reveals some interesting differences. The means are different for females and males $(t=2.074, p<.05)$, with males more controlled with respect to females. A comparison of the density distribution for gender groups shows they are not equivalent $(p<$ .05). The visual analysis of the two distributions highlights that the males are more concentrated around the mean value (see Fig. 3a), although the Fligner-Killeen test does not permit to exclude the homogeneity of variances $(F(1,131)=2.288, p=.23)$.

From our sample, we extract three age groups with comparable sizes: group A includes students aged between 18-19 years old $\left(n_{A}=50\right)$; group $\mathrm{B}$ students aged 20$21\left(n_{B}=43\right)$; group $C$ students over $21\left(n_{C}=40\right)$. In group A there are novices, i.e. students who have recently graduated. Group B consists of students who obtained their high school degree at least one year ago, in some cases with previous experiences in other degree courses. Group $\mathrm{C}$ is more heterogeneous, frequently the members have had previous academic experience. The mean values for the groups, from A to C, are .057 (.792), .107 (.759), and $-.186(.620)$ respectively (standard deviations in parenthesis). The differences are not statistically significant $(F(2.130)=1.901, p=.15)$. A visual inspection of the density distributions (see Fig. 3b) highlights some differences which are not significant $(p>.2)$, with more variability in the scores distribution in the younger with respect to older students. Group $\mathrm{C}$ shows more controlled and homogeneous scores.

\section{Person-centred analysis}

Using the results of the dimensional analysis, we classified subjects into groups with similar motivational profiles and constructed clusters of subjects who are characterised by similar combinations of motivations. The person-centred analysis, according to the study of Vansteenkiste (2009), permits also to verify the external validity of the results of this study. In the study [33], the authors have adopted a modified version of the Self-Regulation Scale (SR-S) [46]. The authors associated three standardized scores to each

Table 6 Factor loadings for the FA (in bold the categories with absolute value of the factor loadings greater than .35)

\begin{tabular}{lllllllllllllllllllllll}
\hline & HEL & JOB & ROL & SCH & TOP & VOC & EXP & MIR & HUM & USE & FAM & PRA & REC & TAR & GRA & SMI & CUR & MIS \\
\hline Loadings & $\mathbf{. 6 8 6}$ & $\mathbf{- . 5 3 7}$ & -.307 & -.204 & -.297 & -.107 & $\mathbf{. 7 6 9}$ & $\mathbf{. 3 6 0}$ & $\mathbf{. 4 5 2}$ & -.192 & $\mathbf{- . 3 5 5}$ & $\mathbf{- . 4 5 2}$ & $\mathbf{- . 4 1 7}$ & .294 & .182 & $\mathbf{. 6 4 8}$ & -.026 & .134 \\
\hline
\end{tabular}


Table 7 Ordering of categories using the outcomes in Table 6 (in bold the categories used in the CFA)

controlled JOB PRA REC FAM ROL TOP SCH USE VOC CUR MIS GRA TAR MIR HUM SMI HEL EXP aUtonomous

subject in the sample, which were calculated from the answers to the modified SR-S. These scores describe the quality of the motivation, controlled vs. autonomous, and the quantity of motivation, related to the total score in the questionnaire. To compare our outcomes, we used the result of the two-parameter logistic model to construct two variables to describe the quality of motivation for each student. The occurrence of categories JOB, REC, PRA, and FAM, permits a controlled motivation score to be allotted to each student, and the occurrence of categories EXP, HUM, HEL, and SMI, provides a score for autonomous motivation. The occurrence of each category is weighted using the estimated slope obtained in the model. To measure the quantity of motivation we counted the total number of categories identified by evaluators.

These three variables can describe the level of controlled and autonomous motivation for each student, and the total quantity of motivations in her/his answers. To obtain comparable results, a procedure of complete-linkage clustering was carried out. The optimal solution is composed of 4 clusters, with $68 \%$ of explained variance, and this result accords well with Vansteenkiste et al. (2009). Comparing the single cluster, some minor differences appear (see Fig. 4). We observe three clusters that are comparable with the clusters obtained by Vansteenkiste et al. (2009), while the fourth cluster is different. It is possible to note a first cluster of students with a prevalence of controlled motivation, this is the 'poor quality motivation' cluster in the Vansteenkiste et al. (2009) paper. A second cluster of students with strong autonomous motivation corresponds to the 'good quality motivation' cluster. A third cluster is composed of students with low total motivation, the quantity of motivation is low for students in this cluster. The sample in this study does not show a cluster of students with a high quantity of motivation. The fourth cluster is

Table 8 Parameters of the logistic model (in bold negative slopes $=$ controlled motivations)

\begin{tabular}{lll}
\hline Category & Intercept (se) & Slope (se) \\
\hline HEL & $.426(.251)$ & $1.005(.463)$ \\
JOB & $-.883(.333)$ & $\mathbf{- 1 . 1 1 8}(.563)$ \\
EXP & $-2.341(.382)$ & $1.763(.947)$ \\
HUM & $-1.933(1.199)$ & $.775(.425)$ \\
FAM & $-2.513(4.622)$ & $\mathbf{- . 5 1 1}(.519)$ \\
PRA & $-2.921(1.627)$ & $\mathbf{- 1 . 0 2 4}(.770)$ \\
REC & $-3.610(.945)$ & $\mathbf{- 1 . 6 4 6}(1.274)$ \\
SMI & $-4.426(.731)$ & $2.040(1.518)$ \\
\hline
\end{tabular}

composed of students with a low level of quantity and not very good quality, i.e. prevalence of controlled motivation.

This discrepancy can probably be ascribed to a slight difference in the variables used: while in our definition the variables used to measure the quantity and the quality of motivation are effectively independent, in the work of Vansteenkiste et al. (2009) the variables are strictly correlated. In fact, the authors used linear combination of the item scores in the SR-S to define quality and quantity of motivation. Despite this minor disagreement, it is extremely interesting to highlight how the analysis carried out in this study allows to compare the results of a free-text questionnaire with the outcomes of a structured test, based on strong theoretical assumptions.

\section{Discussion}

The examination of motivations that drive first year undergraduate students to choose a university nursing course has been the focus of the present research.

In the present study, a set of 18 categories was developed. The categories, obtained applying a thematic analysis to self-reported statements about the choice of nursing degree course, are in line with findings in research literature both in term of typology and relative frequencies [17-22].

This research represents a step forward in the direction of a deep interpretation of students' motivation. Indeed, it proposes a methodology, organizing the categories within the theoretical framework of SDT. The dimensional analysis carried out in this study has shown that nursing students' motivations can be organized along one dimension, corresponding to the controlled/autonomous pattern of the SDT. The distribution of the categories reproduces a classification in which there are categories related to controlled motivation (JOB, PRA, REC and FAM), and categories related to autonomous motivation (SMI, HEL, EXP and HUM).

In a person-centred context, the estimation of the parameters of the unidimensional model permitted us to obtain motivational profiles for students on a nursing degree course. These profiles were in line with the results of other studies that used scales to evaluate student motivation, and were useful in distinguishing between quality and quantity in personal motivation [33]. Three motivational clusters that are comparable with the clusters obtained by Vansteenkiste et al. (2009), were identified: a) students with good quality motivation profile (high autonomous and low controlled); b) students with a poor quality motivation profile (low autonomous and 


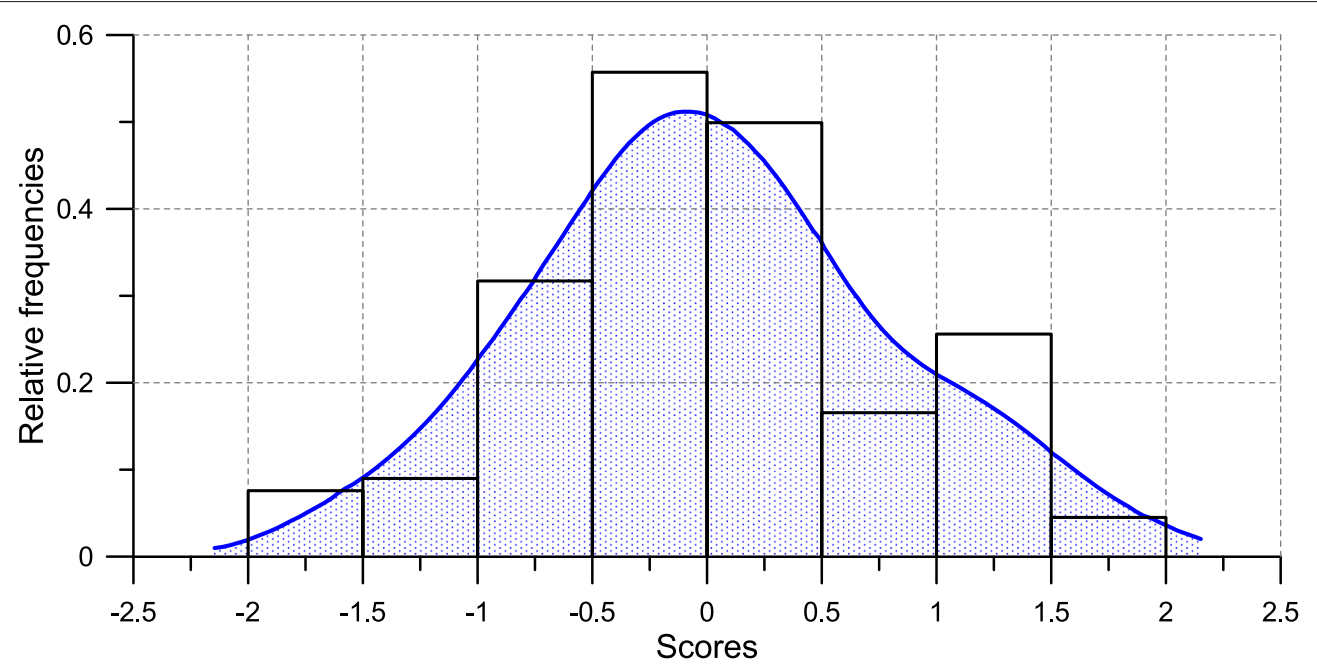

Fig. 2 Distribution of the motivational scores

high controlled); c) students with low quantity motivation profile (low autonomous and low controlled). The fourth identified cluster was different: students with a low level of quantity and not very good quality (i.e. prevalence of controlled motivation).

The use of the SDT framework has allowed to obtain a coherent interpretation of the students answers and has created the possibility to clusterise the nursing students into categories according to their motivational profiles. This has made it possible to compare the results of our study with studies carried out in other academic contexts and using different tools.

The application of the methodology proposed here can permit educators to obtain a more homogeneous vision of the motivations and reasons why students enrol on an academic nursing course. This vision can also help to improve academic policies and learning strategies aimed at dealing with problems related to retention and attrition rates in nursing courses.

Given the international nursing shortage, with nursing student retention acknowledged as a priority, strategic approaches to enhance their retention are essential. Knowing the reasons for choosing nursing studies is important for educators in order to foster and support undergraduate student motivation. The study of motivation in this context is usually aimed at measuring the quantity of motivation. The application of the SDT framework also allow to take into account the quality of personal motivation, in terms of controlled vs. autonomous motivation.

In different context, some studies show that students with an autonomous profile are more persistent in an academic curriculum than students with other motivational profiles [33, 34]. In addition, intrinsic motivation can

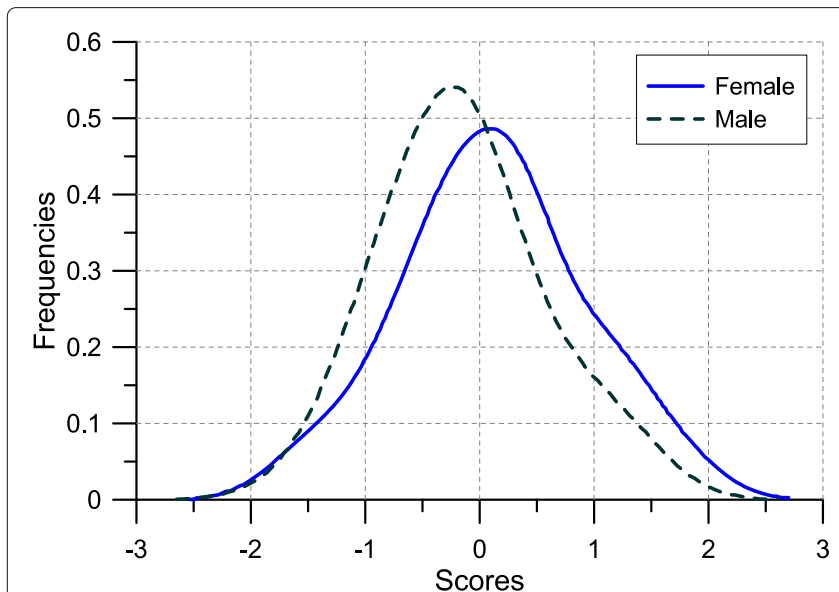

(a)

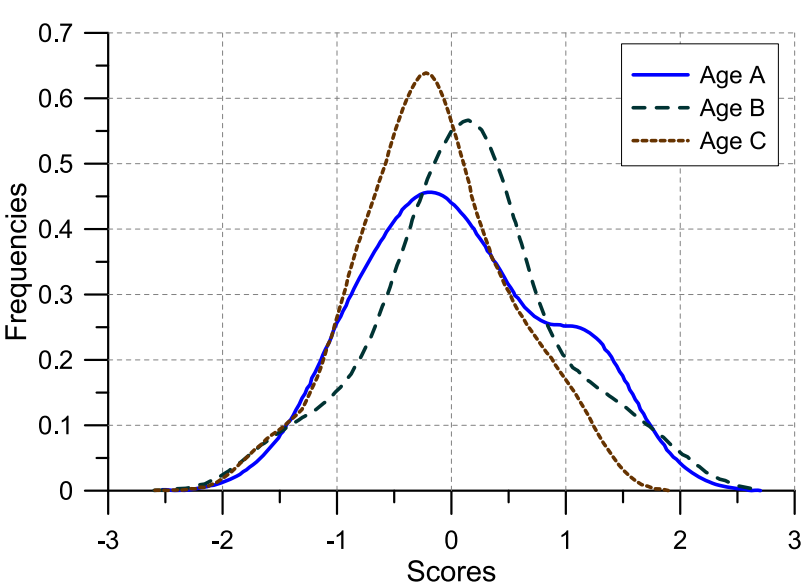

(b)

Fig. 3 Scores for gender (a) and age (b) groups 


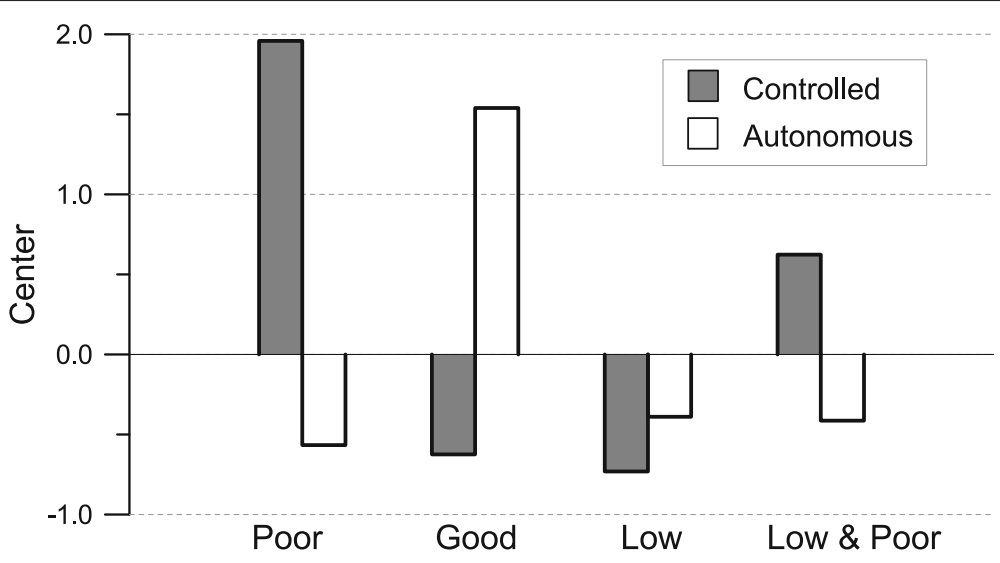

Fig. 4 Motivational clusters

also serve to prevent academic disengagement [29]. This knowledge should make it possible to implement effective strategies aimed at reducing attrition and improving academic success. In fact, as SDT argues, the social environment is fundamental in modifying motivation. Interpersonal environments that are autonomy supportive enhance autonomous motivation and promote learning [47]. On the other hand, controlling environments reduce autonomous motivation and increase controlling motivation.

Promoting specific interventions and activities to support both lessons and internships, may encourage or reinforce motivational aspects already present in students that are essential for this typology of study and profession. One modality would be to offer opportunities for consultation and confrontation, activities in which students can discuss, analyse and reflect on their continuous study experiences and internships that are provided within the nursing course. Another approach would be to make lessons more interactive, with the use of simulation activities, workshops, discussions, reflections, etc. These activities may facilitate the creation of educational environments that allow students to satisfy their basic needs for autonomy, competence and relatedness, and contribute to retention in nursing studies. Further research is needed to evaluate the efficacy of these autonomous supportive interventions, in terms of modification or preservation of the good quality of motivations.

\section{Limitation and future research}

This study has some limitations. To validate the results of this study, further studies in other social and cultural contexts, using also other instruments instead of open questions, such as multiple choice questions, structured interviews, focus groups, etc., are needed.

This study represent a first step to better understand the association between the motivational profile of nursing students and learning success and rate of attrition.
In fact, intrinsic motivation is expected to be associated with more successful student learning outcomes and success over time, than controlled motivation. Furthermore, intrinsically motivated students will probably persist much more in academic tasks. To investigate the validity of these results following the students along their academic career may be indicated.

The cross-sectional nature of this study did not permit to obtain causal relationships between motivations and other situational or dispositional individual traits, such as test anxiety [48]. Only a longitudinal study can help to better understand the evolution of individual motivations and the richer dynamic of interactions between personal variables and other characteristics of the context. Moreover, a wider comparison is needed to verify the validity of the procedure proposed and to improve the description of the possible 'motivational landscapes' which are most favourable to the academic success of nursing students.

Another possible further advance of the present study is the opportunity to develop a new quantitative survey, that could be administered to students after their admission to the degree course, which would investigate well known motivational factors for choosing a nursing career within the framework of SDT.

Despite the above limitations, this study offers initial empirically based evidence of a common motivational pattern characterising students on a nursing degree course. The SDT appears to be a good theoretical framework to describe and analyse this pattern, independently of individual and contextual differences.

\section{Conclusion}

This study analysed within the theoretical framework of SDT the answers to open questions aimed at investigating the self-reported motivations of nursing students in the first year of their degree course. It proposed a 
methodology to overcome some of the biases typical of self-reported data, integrating the qualitative analysis of the nursing students' statements with multidimensional scaling techniques aimed at interpreting the results of the qualitative analysis in the framework of SDT.

For this purpose, we analysed the student nurses' answers using both qualitative and quantitative methods. The qualitative analysis allowed us to collect a large quantity of data about study choices. The aim of this analysis was to identify the main reasons students indicate to motivate their choice of the nursing course. A set of 18 categories was developed. The quantitative analysis utilised the SDT framework to organize these categories along a continuum ranging from controlled to autonomous motivation.

Through adoption of a person-centred approach, four motivational profiles were identified: a) students with good quality motivation profile; b) students with poor quality motivation profile; c) students with low quantity motivation profile; d) students with low quantity and poor quality motivation profile.

The significance of this study includes the opportunity to understand nursing students' reasons within the theoretical framework of SDT, a well-grounded model able to offer useful information to educators, in order to plan effective strategies to foster student motivation, to enhance student retention and successful outcomes, to prevent student attrition and prepare students to enter the workforce.

\section{Abbreviations}

SDT: Self-determination theory; CFA: Confirmatory factor analysis; FA: Factor analysis

\section{Acknowledgements}

The authors gratefully acknowledge the collaboration of students participating in this study.

\section{Funding}

This study received no funding.

\section{Availability of data and materials}

The datasets used and analysed during the current study are available from the corresponding author on reasonable request.

\section{Authors' contributions \\ LM conceived and designed the study, acquired the data, performed the thematic analysis, and contributed to interpretation of the data analysis. LM undertook the preliminary drafting of the paper and revised the manuscript. LS performed the thematic analysis, dimensional and person-centred analysis and interpretation of data. MA contributed substantially to the overall design and the revision of the manuscript. MA checked the procedure, and contributed to interpretation of the data analysis. All authors read and approved the final version of the manuscript.}

\section{Ethics approval and consent to participate}

According to the local ethical policy, no prior formal authorization approval by the Ethics Committee was necessary. We communicated the qualitative study design to the Institutional board of the Undergraduate Nursing Course guaranteeing that ethical standards would be met and we received approval.
All participants were given detailed information about the study. Data collection was carried out only after obtaining voluntary informed consent from students. Participants gave informed consent by ticking appropriate box in the online questionnaire.

\section{Consent for publication}

Not applicable.

\section{Competing interests}

The authors declare that they have no competing interests.

\section{Publisher's Note}

Springer Nature remains neutral with regard to jurisdictional claims in published maps and institutional affiliations.

Received: 22 March 2018 Accepted: 22 April 2019

Published online: 10 June 2019

References

1. Buchan J, Aiken L. Solving nursing shortages: a common priority. J Clin Nurs. 2008;17(24):3262-8. https://doi.org/10.1111/j.1365-2702.2008. 02636.x.

2. Cometto G, Scheffler R, Liu J, Maeda A, Tomblin-Murphy G, Hunter D, Campbell J. Health Employment and Economic Growth: an Evidence Base. In: In: Buchan J, Dhillon I, Campbell J, editors. Geneva: World Health Organization; 2016. p. 1-26.

3. Cameron J, Roxburgh M, Taylor J, Lauder W. Why students leave in the uk an integrative review of the international research literature. J Clin Nurs. 2011;20(7-8):1086-96. https://doi.org/10.1111/j.1365-2702.2010.03328.x.

4. Dante A, Petrucci C, Lancia L. European nursing students' academic success or failure: A post-bologna declaration systematic review. Nurse Educ Today. 2013;33(1):46-52. https://doi.org/10.1016/j.nedt.2012.10.001.

5. Eick SA, Williamson GR, Heath $V$. A systematic review of placement-related attrition in nurse education. Int J Nurs Stud. 2012;49(10):1299-309. https://doi.org/10.1016/j.ijnurstu.2011.12.004.

6. Hamshire C, Willgoss TG, Wibberley C. Should i stay or should i go? a study exploring why healthcare students consider leaving their programme. Nurse Educ Today. 2013;33(8):889-95. https://doi.org/10. 1016/j.nedt.2012.08.013.

7. Pitt V, Powis D, Levett-Jones T, Hunter S. Factors influencing nursing students' academic and clinical performance and attrition: An integrative literature review. Nurse Educ Today. 2012;32(8):903-13. https://doi.org/ 10.1016/j.nedt.2012.04.011.

8. ten Hoeve Y, Castelein S, Jansen WS, Jansen GJ, Roodbol PF. Nursing students' changing orientation and attitudes towards nursing during education: A two year longitudinal study. Nurse Educ Today. 2017:48: 19-24. https://doi.org/10.1016/j.nedt.2016.09.009.

9. Urwin S, Stanley R, Jones M, Gallagher A, Wainwright P, Perkins A Understanding student nurse attrition: Learning from the literature. Nurse Educ Today. 2010;30(2):202-7. https://doi.org/10.1016/j.nedt.2009.07.014

10. Cameron J, Roxburgh M, Taylor J, Lauder W. An integrative literature review of student retention in programmes of nursing and midwifery education: why do students stay?: Review of student retention in programmes of nursing and midwifery education. J Clin Nurs. 2011;20(9-10):1372-82. https://doi.org/10.1111/j.1365-2702.2010.03336.x

11. Jeffreys MR. Nursing Student Retention: Understanding the Process and Making a Difference. New York: Springer; 2012.

12. Wray J, Barrett D, Aspland J, Gardiner E. Staying the course: Factors influencing pre-registration nursing student progression into year 2-a retrospective cohort study. Int J Nurs Stud. 2012;49(11):1432-42. https:// doi.org/10.1016/j.jinurstu.2012.06.006.

13. Jeffreys MR. Jeffreys's nursing universal retention and success model: Overview and action ideas for optimizing outcomes a-z. Nurse Educ Today. 2015;35(3):425-31. https://doi.org/10.1016/j.nedt.2014.11.004

14. Price $S$. Future directions for career choice research in nursing: a discussion paper. Int J Nurs Stud. 2009;46(2):268-76. https://doi.org/10. 1016/j.jinurstu.2008.07.011.

15. Tinto V. Leaving College: Rethinking the Causes and Cures of Student Attrition. Chicago: University of Chicago Press; 1993. 
16. Skatova A, Ferguson E. Why do different people choose different university degrees? motivation and the choice of degree. Front Psychol. 2014:5:1244. https://doi.org/10.3389/fpsyg.2014.01244.

17. Jirwe $M$, Rudman $A$. Why choose a career in nursing?. J Adv Nurs. 2012;68(7):1615-23. https://doi.org/10.1111/j.1365-2648.2012.05991.x.

18. Larsen PD, McGill JS, Palmer SJ. Factors influencing career decisions: perspectives of nursing students in three types of programs. J Nurs Educ. 2003;42(4):168-73.

19. Miers ME, Rickaby CE, Pollard KC. Career choices in health care: Is nursing a special case? a content analysis of survey data. Int J Nurs Stud. 2007;44(7):1196-209. https://doi.org/10.1016/j.jinurstu.2006.04.010.

20. Mooney M, Glacken M, O'Brien F. Choosing nursing as a career: A qualitative study. Nurse Educ Today. 2008;28(7):385-92. https://doi.org/ 10.1016/j.nedt.2007.07.006.

21. Wilkes $L$, Cowin $L$, Johnson $M$. The reasons students choose to undertake a nursing degree. Collegian. 2015;22(3):259-65. https://doi.org/10.1016/j. colegn.2014.01.003.

22. Zysberg L, Berry DM. Gender and students' vocational choices in entering the field of nursing. Nurs Outlook. 2005;53(4):193-8. https://doi.org/10. 1016/j.outlook.2005.05.001.

23. Marcinowicz L, Owlasiuk A, Slusarska B, Zarzycka D, Pawlikowska T. Choice and perception of the nursing profession from the perspective of polish nursing students: a focus group study. BMC Med Educ. 2016;16(1): 243. https://doi.org/10.1186/s12909-016-0765-3.

24. Deci EL, Ryan RM. The "what" and "why" of goal pursuits: Human needs and the self-determination of behavior. Psychol Inq. 2000;1 1(4):227-68.

25. Ryan RM, Deci EL. Intrinsic and extrinsic motivations: Classic definitions and new directions. Contemp Educ Psychol. 2000;25(1):54-67. https://doi. org/10.1006/ceps.1999.1020.

26. Vallerand RJ, Ratelle CF. Handbook of Self-determination Research. In: In: Deci EL, Ryan RM, editors. Rochester: University of Rochester Press; 2002. p. 37-63.

27. Richardson M, Abraham C, Bond R. Psychological correlates of university students' academic performance: A systematic review and meta-analysis. Psychol Bull. 2012;138(2):353-87. https://doi.org/10.1037/a0026838.

28. Niemiec CP, Ryan RM. Autonomy, competence, and relatedness in the classroom: Applying self-determination theory to educational practice. Theory Res Educ. 2009;7(2):133-44. https://doi.org/10.1177/ 1477878509104318.

29. Taylor G, Jungert T, Mageau GA, Schattke K, Dedic H, Rosenfield S, Koestner R. A self-determination theory approach to predicting school achievement over time: the unique role of intrinsic motivation. Contemp Educ Psychol. 2014;39(4):342-58. https://doi.org/10.1016/j.cedpsych. 2014.08.002.

30. Kusurkar RA, Ten Cate TJ, Vos CMP, Westers P, Croiset G. How motivation affects academic performance: a structural equation modelling analysis. Adv Health Sci Educ: Theory Pract. 2013;18(1):57-69. https://doi.org/10.1186/1472-6920-13-87.

31. Vansteenkiste M, Simons J, Lens W, Sheldon KM, Deci EL. Motivating learning, performance, and persistence: the synergistic effects of intrinsic goal contents and autonomy-supportive contexts. J Pers Soc Psychol. 2004;87(2):246-60. https://doi.org/10.1037/0022-3514.87.2.246.

32. Vallerand RJ, Blssonnette R. Intrinsic, extrinsic, and amotivational styles as predictors of behavior: A prospective study. J Pers. 1992;60(3):599-620. https://doi.org/10.1111/j.1467-6494.1992.tb00922.x.

33. Vansteenkiste M, Sierens E, Soenens B, Luyckx K, Lens W. Motivational profiles from a self-determination perspective: The quality of motivation matters. J Educ Psychol. 2009;101 (3):671-88. https://doi.org/10.1037/ a0015083.

34. Ratelle C, Guay F, Vallerand R, Larose S, Senécal C. Autonomous, controlled, and amotivated types of academic motivation: A person-oriented analysis. J Educ Psychol. 2007;99(4):734-46. https://doi. org/10.1037/0022-0663.99.4.734.

35. Wouters A, Bakker AH, van Wijk IJ, Croiset G, Kusurkar RA. A qualitative analysis of statements on motivation of applicants for medical school. BMC Med Educ. 2014;14:200. https://doi.org/10.1186/1472-6920-14-200.

36. Bryman A, Burgess RG. Analyzing Qualitative Data. London: Routledge; 1994.

37. Holgado-Tello FP, Chacón-Moscoso S, Barbero-García I, Vila-Abad E. Polychoric versus pearson correlations in exploratory and confirmatory factor analysis of ordinal variables. Qual \& Quant. 2010;44(1):153-66. https://doi.org/10.1007/s11135-008-9190-y.
38. Gorsuch RL. Factor Analysis. Philadelphia: Sauders; 1974. https://doi.org/ 10.1002/0471264385.wei0206.

39. Cattell RB. The Scientific Use of Factor Analysis in Behavioral and Life Sciences. New York: Plenum Press; 1978. https://doi.org/10.1007/978-14684-2262-7.

40. Hair JFJ, Anderson RE, Tatham RL, Grablowsky BJ. Mutivariate Data Analysis. Tulsa: PPC Books; 1979.

41. MacCallum RC, Widaman KF, Zhang S, Hong S. Sample size in factor analysis. Psychol methods. 1999;4(1):84. https://doi.org/10.1037/1082989X.4.1.84.

42. McNeish D. Missing data methods for arbitrary missingness with small samples. J Appl Stat. 2017;44(1):24-39. https://doi.org/10.1080/02664763. 2016.1158246.

43. Dziuban CD, Shirkey EC. When is a correlation matrix appropriate for factor analysis? some decision rules. Psychol Bullet. 1974;81 (6):358. https://doi.org/10.1037/h0036316.

44. Kaiser HF. A second generation little jiffy. Psychometrika. 1970;35(4): 401-15. https://doi.org/10.1007/bf02291817.

45. Bartholomew DJ. Factor analysis for categorical data. J Royal Stat Soc. Series B (Methodological). 1980293-321.

46. Ryan RM, Connell JP. Perceived locus of causality and internalization: Examining reasons for acting in two domains. J Personal Soc Psychol. 1989;57(5):749-61. https://doi.org/10.1037/0022-3514.57.5.749.

47. Lyness JM, Lurie SJ, Ward DS, Mooney CJ, Lambert DR. Engaging students and faculty: implications of self-determination theory for teachers and leaders in academic medicine. BMC Med Educ. 2013;13(1): 151. https://doi.org/10.1186/1472-6920-13-151.

48. Messineo L, Gentile M, Allegra M. Test-enhanced learning: analysis of an experience with undergraduate nursing students. BMC Med Educ. 2015;15(1):182. https://doi.org/10.1186/s12909-015-0464-5.
Ready to submit your research? Choose BMC and benefit from:

- fast, convenient online submission

- thorough peer review by experienced researchers in your field

- rapid publication on acceptance

- support for research data, including large and complex data types

- gold Open Access which fosters wider collaboration and increased citations

- maximum visibility for your research: over $100 \mathrm{M}$ website views per year

At $\mathrm{BMC}$, research is always in progress.

Learn more biomedcentral.com/submissions 